\title{
Dictyostelium discoideum spore germination: increases in proteinase activity are not directly coupled to the emergence of myxamoebae
}

\author{
Michael J. North, ${ }^{*} \dagger$ David A. Cotter and Karl J. Franek \\ Department of Biological Sciences, University of Windsor, Windsor, Ontario N9B 3P4, Canada
}

(Received 12 September 1989; revised 2 January 1990; accepted 25 January 1990)

\begin{abstract}
The accumulation of proteinase activity during the germination of Dictyostelium discoideum spores was examined under conditions in which the timing of germination events was varied. Spores had a single major proteinase, the aspartic proteinase ddAP58 (proteinase E), while the extracellular matrix which surrounds the spores in the fruiting body contained a number of lower- $M_{\mathrm{r}}$ cysteine proteinases, the most active being ddCP18. Very little peptide-nitroanilide-hydrolysing activity was detectable in spores, although some was associated with the matrix. During spore germination there were large increases in activity towards $N$-carbobenzoxy-L-tyrosyl-L-lysyl-Larginine 4-nitroanilide and $N$-benzoyl-L-prolyl-L-phenylalanyl-L-arginine 4-nitroanilide. The enzymes responsible for these activities (referred to as ZYKRase and BzPFRase respectively) were not identical as BzPFRase was much more sensitive to the cysteine proteinase inhibitor E-64 than was ZYKRase. When spores were heatactivated, the increases in activity coincided with the emergence of myxamoebae and the appearance of cysteine proteinases detected using electrophoresis in gelatin gels. For autoactivated spores, emergence was delayed by 0.5 to $1 \mathrm{~h}$ and proteinase accumulation lagged slightly behind emergence. If the spores were activated with DMSO, or if heat-activated spores were treated with sucrose after swelling, proteinase accumulation proceeded more rapidly than emergence. Thus temporal control of the accumulation of proteinases during germination varies according to the conditions used. In heat-activated spores, the timing of the inerease was similar to that observed previously for $\beta$-glucosidase and trehalase, but the temporal controls were not the same as those for the latter enzymes when the other activation conditions were used. The results show that proteinase accumulation is not directly coupled to emergence but could be more closely linked to the late swelling stage which precedes emergence.
\end{abstract}

\section{Introduction}

Proteinases represent an interesting group of enzymes for studying the mechanisms involved in regulating enzyme activities during the life cycle of the cellular slime mould Dictyostelium discoideum. The most active proteinases are of the aspartic and cysteine types, and while the aspartic proteinase level remains relatively constant throughout both the vegetative and developmental phases, cysteine proteinases are subject to nutritional and developmental regulation (North, 1985, 1988; North et al., 1988). Multiple forms of cysteine proteinase are present and these differ from one another

$\dagger$ Permanent address: Department of Biological and Molecular Sciences, School of Natural Sciences, University of Stirling, Stirling FK9 4LA, UK.

Abbreviations: Bz, $\mathrm{N}$-benzoyl; $\mathrm{Z}, \mathrm{N}$-benzyloxycarbonyl; Nan, 4nitroanilide; BzPFRase, Bz-Pro-Phe-Arg-Nan hydrolysing activity; ZYKRase, Z-Tyr-Lys-Arg-Nan hydrolysing activity; E-64, L-3-carboxy-trans-2,3-epoxypropionyl-L-leucylamido-(4-guanidino)-butane. in their regulation (North, 1988; North et al., 1988) and secretion (North et al., 1990). The net cysteine proteinase activity is greatest during the vegetative phase, but declines during development as aggregation and then fruiting body formation take place. Cysteine proteinase genes which are not expressed during growth are switched on during this period (Pears et al., 1985; Williams et al., 1985); however, the products of these genes have not yet been identified. Spores have very low cysteine proteinase activity, but activity accumulates during germination (Jackson \& Cotter, 1984; North \& Cotter, 1984).

As part of a study aimed at understanding the factors involved in the control of cysteine proteinase activity and the relationship between the regulation and function of these enzymes, we have conducted a more detailed study of the changes which occur during germination. $D$. discoideum produces a variety of hydrolytic enzymes whose activities are differentially regulated throughout the different phases of the life cycle, including germina- 
tion (Tisa \& Cotter, 1980). Some, like the cysteine proteinases, are either absent from spores or are present at low levels (Seshadri et al., 1986), and then accumulate during germination (Chan \& Cotter, 1982a, $b$ ). If spores are activated by incubation at $45^{\circ} \mathrm{C}$ (heat activation) the accumulation of trehalase and $\beta$-glucosidase coincides with the emergence of myxamoebae from spore coats as does the increase in cysteine proteinase activity (Jackson $\&$ Cotter, 1984; North \& Cotter, 1984). When spores are activated by other agents, for example DMSO or urea, trehalase and $\beta$-glucosidase accumulation are temporally separated from emergence (Chan \& Cotter, 1982a,b). We wished to determine whether or not this was also true for cysteine proteinase expression, and have measured changes in proteinase activity in spores exposed to different conditions which alter the timing of germination events. The results show that cysteine proteinase expression is in fact not directly linked to the emergence phase. Its regulation is not, however, identical to that of either trehalase or $\beta$-glucosidase.

\section{Methods}

Organism and sample preparation. Spores of Dictyostelium discoideum strain SG1 (ATCC 44840), a spontaneous germination mutant (Cotter \& Dahlberg, 1977), and the wild-type strain NC4H (ATCC 28245) were prepared from mature fruiting bodies as described previously (Cotter \& Raper, 1968). Spores were activated by incubation at $45^{\circ} \mathrm{C}$ for $30 \mathrm{~min}$ (Cotter \& Raper, 1968) or by incubation with $20 \%(\mathrm{v} / \mathrm{v}$ ) DMSO for $30 \mathrm{~min}$ following which the DMSO was removed from the spores by filtration through a $1.2 \mu \mathrm{m}$ filter (Cotter et al., 1976; Giri \& Ennis, 1977). For autoactivation, spores were washed by centrifugation to remove the autoinhibitor and were transferred into germination buffer (Dahlberg \& Cotter, 1978). Spores were incubated in $10 \mathrm{~mm}-$ potassium phosphate buffer, $\mathrm{pH} 6.5$, at $23.5{ }^{\circ} \mathrm{C}$. The percentages of spores which were swollen and which had developed to emerged myxamoebae were determined microscopically (Cotter \& Raper, 1968).

Samples of germinating spores were removed periodically and the cells collected by low-speed centrifugation at room temperature in 15 $\mathrm{ml}$ Corex centrifuge tubes. The cell pellets were frozen immediately. Extracts were prepared from frozen spores in $10 \mathrm{~mm}$-potassium phosphate buffer, $\mathrm{pH} 6 \cdot 5$, containing $0.1 \%$ Triton $\mathrm{X}-100$, by disruption with glass beads (North \& Cotter, 1984) and were either stored frozen or used immediately for assaying proteinase activity and electrophoretic analysis. Storage of cell pellets had no apparent effect on proteinase activity.

Proteinase analysis. Proteinase activity was determined using the chromogenic substrates Bz-Pro-Phe-Arg-Nan, Z-Tyr-Lys-Arg-Nan and Z-Arg-Arg-Nan in micro-assays conducted in multi-well plates (North et al., 1990). Activity was determined from the release of 4nitroaniline measured at $405 \mathrm{~nm}$ and is given in units of nmol released $\min ^{-1}$ (mg protein) $)^{-1}$. Protein was determined by the method of Bradford (1976) using bovine albumin as standard.

Electrophoretic analysis of proteinases was done by the gelatin-SDSPAGE technique using mini-gels (North et al., 1990). Unless otherwise indicated, proteinases were detected by incubating gels in acetic $\mathrm{acid} / \mathrm{sodium}$ acetate buffer, $\mathrm{pH} 4 \cdot 0$, containing $1 \mathrm{mM}$-DTT, at $23 \cdot 5^{\circ} \mathrm{C}$.
Chemicals. Gelatin, DMSO, DTT and Bz-Pro-Phe-Arg-Nan were supplied by Sigma, Z-Arg-Arg-Nan by Novabiochem and Z-Tyr-LysArg-Nan by Bachem. E-64 was a product of The Peptide Institute and was obtained from Scientific Marketing Associates. All other chemicals were of the highest purity commercially available.

\section{Results}

The proteinase activity of germinating spores was measured using Bz-Pro-Phe-Arg-Nan, Z-Arg-Arg-Nan and Z-Tyr-Lys-Arg-Nan, the three peptide nitroanilides which are most rapidly hydrolysed by extracts prepared from vegetative myxamoebae (North et al., 1990). All were initially selected as putative cysteine proteinase substrates, although the enzymes of vegetative cells which are responsible for the hydrolysis of the three substrates are not identical to one another (North et al., 1990). Activity was low in dormant spores, but some, notably the Z-Tyr-Lys-Arg-Nan-hydrolysing activity (referred to as ZYKRase), were present in the extracellular matrix which surrounds the spores in the fruiting body (Table 1). The specific activities for the matrix were relatively high because the latter contains 5 - to 10 -fold less protein than spore preparations (Seshadri et al., 1986). During the germination of heat-activated spores of strain $\mathrm{NC4}$ there was a significant increase in ZYKRase and in the activity towards Bz-Pro-Phe-ArgNan (BzPFRase), although with Z-Arg-Arg-Nan (ZRRase) an increase was not always apparent. The activity levels of the emerged myxamoebae differed from those of growing cells, however. The ZYKRase activity was higher, whereas both BzPFRase and ZRRase levels were lower than in vegetative cells. The amount of nitroanilide-hydrolysing activity detectable in the germination buffer was very low throughout germination and did not make a significant contribution to the total activity in the suspension (data not shown).

With extracts prepared from emerged myxamoebae, the hydrolysis of each of the substrates was blocked by E64, an inhibitor specific for cysteine proteinases (Kirschke \& Barrett, 1987). BzPFRase and ZRRase were much more sensitive to inhibition than was ZYKRase. At a concentration of $10 \mu \mathrm{g} \mathrm{ml}^{-1}$, E-64 inactivated over $90 \%$ of the BzPFRase and ZRRase activity, whereas ZYKRase was inhibited by only $70 \%$ by E-64 at $100 \mu \mathrm{g} \mathrm{ml}^{-1}$. This suggested that both BzPFRase and ZRRase were due to cysteine proteinases, but that ZYKRase may not have been. BzPFRase and ZRRase activities were also maximal in the presence of 1 mM-DTT, while ZYKRase activity was unaffected by this reducing agent.

An increase in BzPFRase activity in heat-activated spores of strain NC4 had previously been shown to coincide with the emergence of myxamoebae from spore 


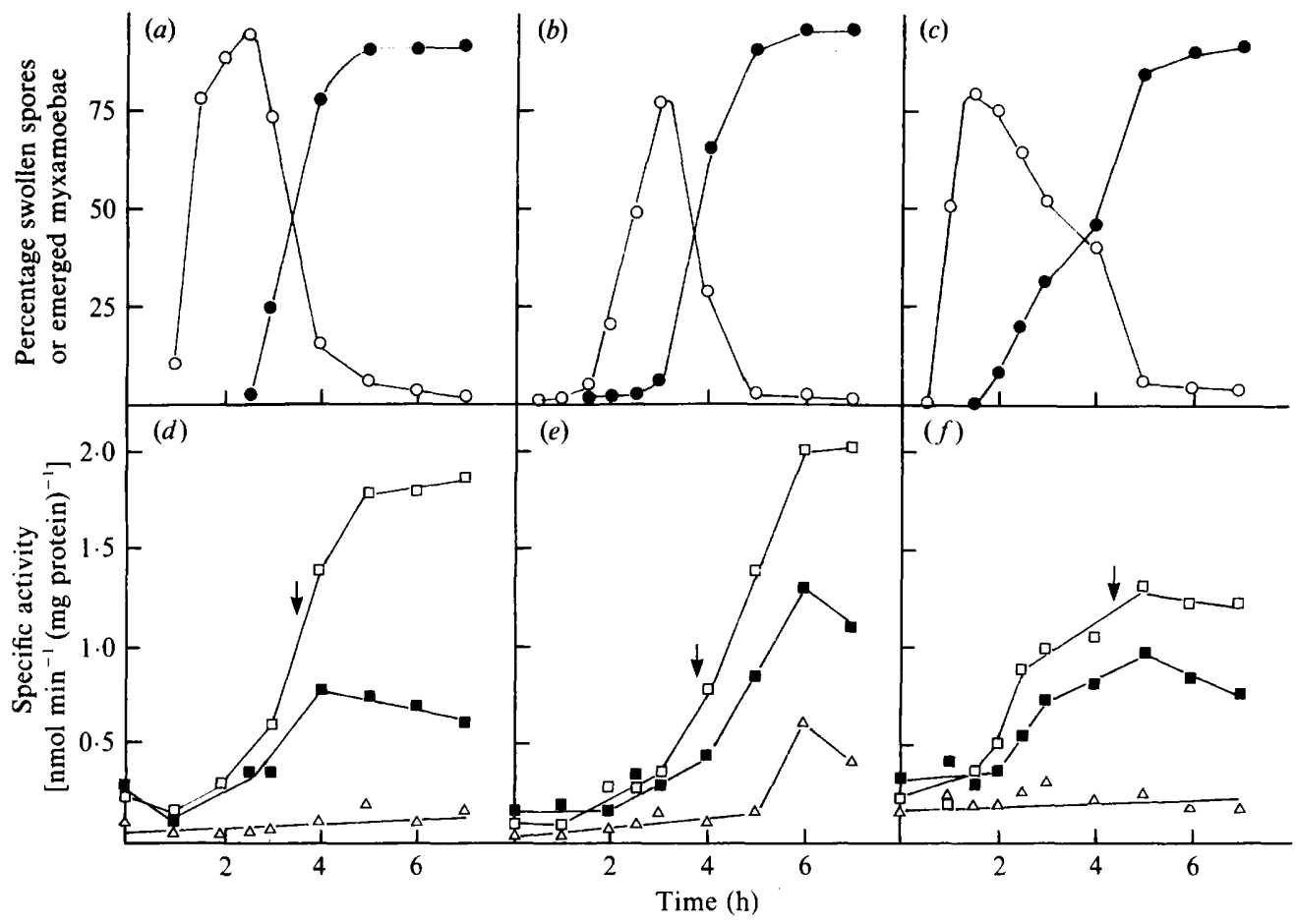

Fig. 1. Changes in proteinase activity during the germination of spores of strain SG1. Spores were $(a, d)$ heat-activated, $(b, e)$ autoactivated or $(c, f)$ DMSO-activated as described in Methods. The arrows indicate the time in which $50 \%$ of the cells had emerged. The spores used in $(a, b, d$ and $e$ ) were from the same population, those for $(c$ and $f)$ were obtained separately. $(a-c)$ Percentage swollen spores $(O)$; percentage emerged myxamoebae $(\bigcirc) .(d-f)$ ZYKRase $(\square)$; BzPFRase $(\square)$; ZRRase $(\triangle)$.

Table 1. Proteinase activity changes during germination

The results are given $\pm \mathrm{SD}$ for the number of determinations indicated in parentheses.

\begin{tabular}{|c|c|c|c|c|c|}
\hline \multirow[b]{2}{*}{ Strain } & \multirow[b]{2}{*}{ Stage } & \multirow{2}{*}{$\begin{array}{l}\text { Mode of } \\
\text { activation }\end{array}$} & \multicolumn{3}{|c|}{ Proteinase activity $\left[\mathrm{nmol} \mathrm{min}^{-1}(\mathrm{mg} \text { protein })^{-1}\right]$} \\
\hline & & & BzPFRase & ZYKRase & ZRRase \\
\hline $\mathrm{NC4}$ & $\begin{array}{l}\text { Matrix } \\
\text { Dormant spores } \\
\text { Emerged myxamoebae } \\
\text { Vegetative myxamoebae }\end{array}$ & Heat & $\begin{array}{l}1.27 \pm 1 \cdot 11(6) \\
0 \cdot 25 \pm 0.18(5) \\
1.51 \pm 0.65(4) \\
5 \cdot 2(1)\end{array}$ & $\begin{array}{l}2.28 \pm 0.76(7) \\
0.37 \pm 0.10(6) \\
5.55 \pm 1.68(4) \\
2.9(1)\end{array}$ & $\begin{array}{l}0 \cdot 14 \pm 0 \cdot 12(6) \\
0 \cdot 10 \pm 0 \cdot 10(6) \\
0.64 \pm 0 \cdot 24(4) \\
1.0(1)\end{array}$ \\
\hline SG1 & $\begin{array}{l}\text { Matrix } \\
\text { Dormant spores } \\
\text { Emerged myxamoebae }\end{array}$ & $\begin{array}{l}\text { Heat } \\
\text { Auto } \\
\text { DMSO }\end{array}$ & $\begin{array}{l}0.79 \pm 1.04(3) \\
0.28 \pm 0.12(4) \\
0.63 \pm 0.19(2) \\
1.25 \pm 0.16(3) \\
0.74(1) \\
3.7(1)\end{array}$ & $\begin{array}{l}2.67 \pm 0.55(3) \\
0.35 \pm 0.10(4) \\
1.93 \pm 0.18(2) \\
1.79 \pm 0.51 \text { (3) } \\
1.18(1) \\
2.5(1)\end{array}$ & $\begin{array}{l}0.14 \pm 0.02(3) \\
0.13 \pm 0.11(4) \\
0.05 \pm 0.07(2) \\
0.51 \pm 0.11(3) \\
0.28(1) \\
1.9(1)\end{array}$ \\
\hline
\end{tabular}

coats (North \& Cotter, 1984), and this was also so for the ZYKRase activity in NC4 (results not shown). To determine whether proteinase accumulation and emergence were always coincident, spores were subjected to conditions which allowed the time-course of germination to be altered. Strain SG1 was used so that autoactivated spores could be examined. After heat activation of SG1 spores, the changes in the activities (Fig. 1) were identical to those observed for NC4, except that a lower maximum specific activity was achieved (see Table 1). With autoactivated spores, both swelling and emergence occurred $0.5 \mathrm{~h}$ to $1 \mathrm{~h}$ later than when heat activation was used, and there was also a slightly longer delay in the accumulation of proteinase activity. Activation with DMSO resulted in earlier swelling, but subsequent emergence was delayed. In this case, however, the increase in proteinase activity was slightly earlier than in heat-activated spores and preceded the emergence of the 
majority of the myxamoebae. The maximum specific activity was attained when only $50 \%$ of myxamoebae had emerged, whereas over $90 \%$ emergence had occurred before heat-activated and autoactivated spores achieved their highest level of activity. Each of these conditions has been tested at least twice, and although slight differences in the timing of events were observed between individual experiments, the relative timing of the proteinase changes to germination events was always the same.

A further alteration to germination was achieved by treating spores with sucrose. At a concentration of $0.25 \mathrm{M}$, sucrose deactivates activated spores which then fail to swell. Accumulation of hydrolases, including cysteine proteinases, does not occur (Cotter et al., 1979; North \& Cotter, 1984). When $0.25 \mathrm{M}$-sucrose was added to spores which had already swollen $(2.5 \mathrm{~h}$ after heat activation) emergence was severely delayed and the increase in proteinase activity did not occur (data not shown). With a lower concentration of sucrose $(0 \cdot 1 \mathrm{M})$, emergence was still delayed but the increase in proteinase activity was unaffected (Fig. 2). The maximum activity was attained when only $35 \%$ of the myxamoebae had emerged. With both NC4 (data not shown) and SG1 (Fig. 2), the maximum specific activity for ZYKRase was slightly higher than in cells to which no sucrose had been added. Sucrose stimulates the secretion of proteinases from vegetative myxamoebae (North et al., 1990), but it did not stimulate the release of activity from germinating spores (results not shown).

Individual Dictyostelium proteinases can be separated and identified using gelatin-SDS-PAGE (North et al., 1988). Prior to germination, both dormant and activated spores contained a major proteinase band with an apparent $M_{\mathrm{r}}$ of 58000 (Fig. 3). Occasionally, a second band with an apparent $M_{\mathrm{r}}$ of 35000 was also present. Neither enzyme was inhibited by E-64 at any concentration tested, and so these were not cysteine proteinases. The $58000-M_{\mathrm{r}}$ proteinase is believed to be proteinase $\mathrm{E}$ (now renamed ddAP58 - Dictyostelium discoideum aspartic proteinase, $M_{\mathrm{r}} \underline{58000)}$ the major aspartic proteinase in $D$. discoideum (North \& Whyte, 1984). This enzyme is present throughout the life cycle but is not readily detected by gelatin-SDS-PAGE in extracts prepared from vegetative cells (North et al., 1988), although it can be detected in both spores and myxamoebae by electrophoresis using haemoglobin-gels under non-denaturing conditions (North \& Cotter, 1984). No extracellular proteinases were detected during germination, but the matrix material which surrounds the spores in the fruiting body contained a number of proteinases of higher mobility, the predominant one of which had an apparent $M_{\mathrm{r}}$ of 18000 . The enzyme responsible, which has been named ddCP18 in accor-

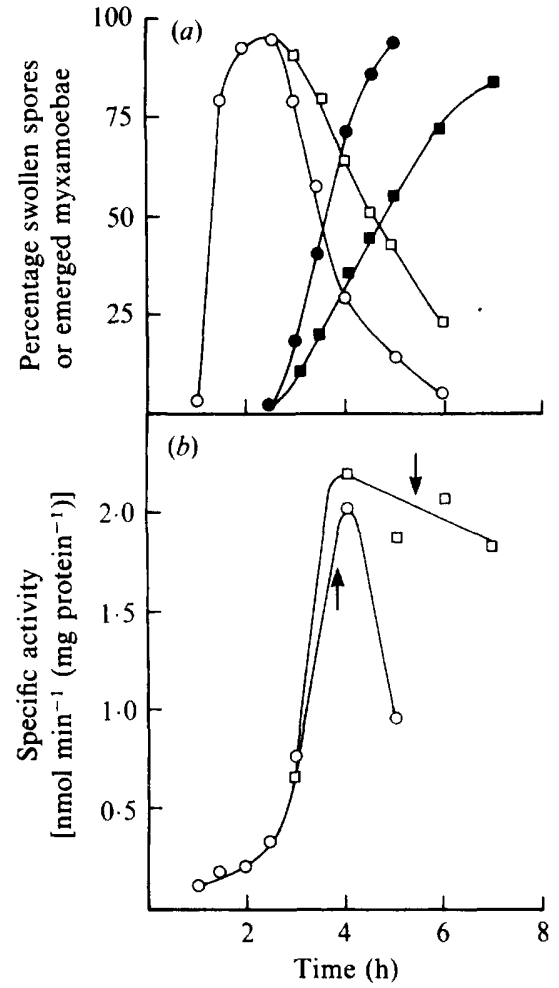

Fig. 2. Effect of sucrose on the changes in proteinase activity during germination of spores of strain SG1. Spores were heat-activated and after $2.5 \mathrm{~h}$ the suspension was divided into two and solid sucrose added to one portion to give a final concentration of $0.1 \mathrm{M}$. The other was left untreated. Arrows, as Fig. 1. $\bigcirc$, O Untreated suspension; $\square, \mathbf{\square}$, sucrose-treated suspension. (a) Percentage swollen spores (open symbols); percentage emerged myxamoebae (filled symbols). (b) ZYKRase.

dance with the nomenclature scheme adopted previously (North et al., 1988), was sensitive to E-64 (complete inhibition at $10 \mu \mathrm{g} \mathrm{ml}^{-1}$ ), and so is considered to be a cysteine proteinase. ddCP18 was not detected in extracts prepared from washed spores.

ddAP58 was present throughout the germination period, but its activity declined and was sometimes barely detectable after the myxamoebae had emerged. The major change in proteinase pattern which accompanied the germination of heat-activated spores was the appearance of a new band 2 to $3 \mathrm{~h}$ after activation (Fig. 3), the same time as the increases in ZYKRase and BzPFRase began (Fig. 1). The mobility of the proteinase in both $7.5 \%$ and $12 \%(\mathrm{w} / \mathrm{v})$ acrylamide gels corresponded to that of ddCP48, the most active proteinase in myxamoebae grown in association with bacteria (North et al., 1988). Like ddCP48, the germination proteinase was inactivated by E-64. Additional bands of slightly lower apparent $M_{\mathrm{r}}$ also appeared, one of which may correspond to a second vegetative enzyme ddCP43. The apparent decline in ddAP58 activity 


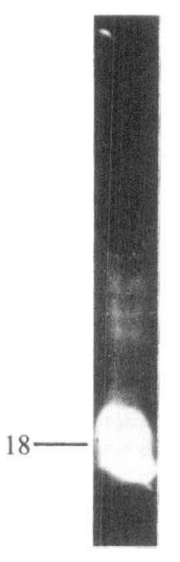

$\mathbf{M}$

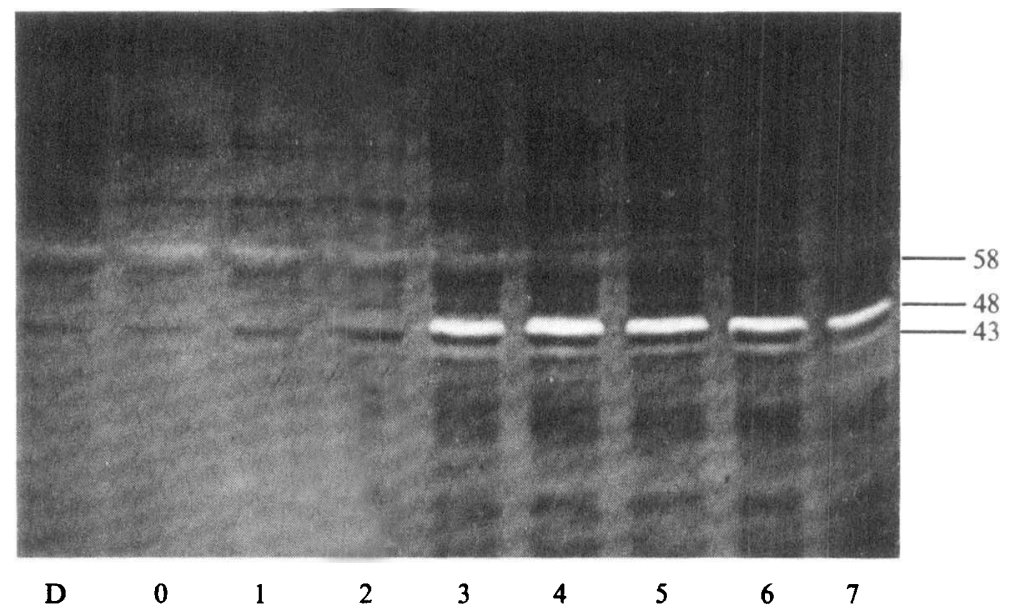

Fig. 3. Proteinase changes during germination of SG1 spores revealed by gelatin-SDS-PAGE. The gel was incubated at pH 4 with $1 \mathrm{mM}-$ DTT. M, extracellular matrix; D, dormant spores; $0-7$, time (in h) after heat-activation. The apparent $M_{\mathrm{r}}$ values $\left(\times 10^{-3}\right)$ of the proteinases are indicated.

coincided with the appearance of ddCP48 and raised the possibility that ddAP58 might not be detectable in some cell preparations, notably those of vegetative myxamoebae, because it is inactivated during electrophoresis by ddCP48 and other cysteine proteinases. To test this possibility, samples prepared from spores were mixed with samples prepared from emerged myxamoebae prior to electrophoresis. However, in these mixtures ddAP58 was still detectable, and so the decline in ddAP58 activity cannot be accounted for simply by inactivation by newly produced cysteine proteinases.

\section{Discussion}

Previous observations on changes in proteinase activity during the germination of heat-activated spores (Jackson \& Cotter, 1984; North \& Cotter, 1984) had indicated that there might be a link between proteinase accumulation and the emergence of myxamoebae. This raised the possibility that the enzymes are required by the cells primarily for feeding when germination is complete rather than for a proteolytic event involved in germination itself. A direct link has, however, been ruled out by the results presented here. The increases in ZYKRase and BzPFRase activities occurred slightly before emergence in DMSO-activated spores and sucrose-treated swollen spores, coincident with emergence in heatactivated spores, but slightly later than emergence in autoactivated spores. These data indicate that there may in fact be a closer correlation with swelling, since regardless of the conditions used for activation, enzyme accumulation commenced during the late swelling stage.

Because there were differences in their dependence on DTT and their inactivation by cysteine proteinase inhibitors, the enzymes responsible for the ZYKRase and BzPFRase cannot be the same, although they would appear to be coordinately regulated during germination. ddCP48, a major cysteine proteinase present in vegetative myxamoebae, was absent from spores but accumulated during germination. Its properties were similar to those of the BzPFRase but different from those of ZYKRase. The nature of the enzyme(s) responsible for ZYKRase activity is of particular interest, as this activity showed the greatest increase during germination, and in strain NC4 the ZYKRase level in emerging myxamoebae exceeded that found in vegetative cells. This suggests that this activity might have a role specific to germination. In vegetative cells, the enzyme(s) responsible for ZYKRase activity are distinct from those involved in the BzPFRase activity as they are not secreted (North et al., 1990) and are apparently cytosolic (M. J. North, unpublished observations). In view of this it is perhaps surprising that ZYKRase activity was found in the matrix material of fruiting bodies. High activity in the matrix is a characteristic of a set of lysosomal enzymes such as trehalase and $\beta$-glucosidase (Seshadri et al., 1986), which are secreted from myxamoebae under conditions where ZYK Rase is confined to the cell (North et al., 1990). It is not yet known whether the ZYKRase enzymes present in either vegetative cells or the matrix are the same as those which accumulate during germination, although no differences in the properties of the activity present at different stages have so far been demonstrated.

It is interesting to compare the effects of using the different modes of activation on proteinase accumulation with those observed with $\beta$-glucosidase and trehalase (Chan \& Cotter, 1982a, b). Autoactivation results in the earlier production of the latter enzymes, 
especially trehalase, the opposite of the situation with ZYK Rase and BzPFRase. Activation with DMSO also advances the time of appearance of $\beta$-glucosidase and trehalase, although not to the same extent as with autoactivation. In this case, the same effect was found with ZYKRase and BzPFRase. Thus the proteinase data do not readily fit with the view proposed previously (Chan \& Cotter, 1982b) that the more 'severe' the activation treatment the later is the resulting increase in enzyme activity. Here autoactivation, the mildest treatment, delayed the increase in proteinase activity. A quantitative shift in ZYKRase, although not BzPFRase, was apparent when spores were activated by DMSO, but this was not as great as the shifts found previously for trehalase (Chan \& Cotter, 1982b). These differences indicate that the controls operating for the proteinases, trehalase and $\beta$-glucosidase may not be directly coordinated and that different factors must influence the production of individual hydrolytic enzymes during germination. In vegetative cells the BzPFRase activity shares a number of features, such as its secretion behaviour and location in lysosomes, with trehalase and $\beta$-glucosidase. In spite of these similarities the accumulation of BzPFRase during germination was more closely coordinated to that of ZYKRase than it was to the other hydrolases even though the ZYKRase of vegetative cells is neither secreted nor lysosomal. Thus proteinase activities may be controlled through mechanisms distinct from those operating over other groups of hydrolases.

M.J.N. wishes to thank the Carnegie Trust for the Universities in Scotland for support. This work was supported, in part, by grants from the Natural Sciences and Engineering Research Council of Canada and a NATO Collaborative Research Grant. We are grateful to Kay Nicol for technical assistance.

\section{References}

BRADFORD, M. M. (1976). A rapid and sensitive method for the quantitation of microgram quantities of protein utilizing the principle of protein-dye binding. Analytical Biochemistry 72, 248254.

Chan, A. H. \& Cotter, D. A. (1982a). The role of expression of $\beta$ glucosidase during spore germination of mutant and wild-type Dictyostelium discoideum. Canadian Journal of Microbiology 28, 740-748.

Chan, A. H. \& CotTer, D. A. (1982b). Spore-activating agents influence the temporal and quantitative activity of $\beta$-glucosidase and trehalase during Dictyostelium discoideum germination. Experimental Mycology 6, 77-83.

COTTER, D. A. \& DAHLBERG, K. R. (1977). Isolation and characterization of Dictyostelium discoideum spore mutants with altered activation requirements. Experimental Mycology 1, 107-115.

COTTER, D. A. \& RAPER, K. B. (1968). Factors affecting the rate of heat-induced spore germination in Dictyostelium discoideum. Journal of Bacteriology 96, 86-92.

COTTER, D. A., GARNISH, F. J. \& TISA, L. S. (1979). The physiological effects of restrictive environmental conditions on Dictyostelium discoideum spore germination. Canadian Journal of Microbiology 25, 24-31.

Cotter, D. A., Morin, J. W. \& O'Connell, R. W. (1976). Spore germination in Dictyostelium discoideum. II. Effects of dimethyl sulfoxide on postactivation lag as evidence for the multistate model of activation. Archives of Microbiology 108, 93-98.

DAHLBERG, K. R. \& CotTer, D. A. (1978). Autoactivation of spore germination in mutant and wild type strains of Dictyostelium discoideum. Microbios 23, 153-166.

GIRI, J. G. \& ENNIS, H. L. (1977). Protein and RNA synthesis during spore germination in the cellular slime mold Dictyostelium discoideum. Biochemical and Biophysical Research Communications 77, 282289.

JACKSON, D. P. \& CotTeR, D. A. (1984). Expression of proteolytic enzymes during Dictyostelium discoideum spore germination. Archives of Microbiology 137, 205-208.

KIRSCHKE, H. \& BARRETT, A. J. (1987). Chemistry of lysosomal proteases. In Lysosomes: Their Role in Protein Breakdown, pp. 193238. Edited by H. Glaumann \& F. J. Ballard. London: Academic Press.

NoRTH, M. J. (1985). Cysteine proteinases of cellular slime moulds. Biochemical Society Transactions 13, 288-290.

NORTH, M. J. (1988). A bacterial factor induces changes in cysteine proteinase forms in the cellular slime mould Dictyostelium discoideum. Biochemical Journal 254, 269-275.

North, M. J. \& CotTer, D. A. (1984). Proteolytic enzyme activity during Dictyostelium discoideum spore germination. Experimental Mycology 8, 47-54.

NORTH, M. J. \& WhYTE, A. (1984). Purification and characterization of two acid proteinases from Dictyostelium discoideum. Journal of General Microbiology 130, 123-134.

NoRTH, M. J., ScotT, K. I. \& Lockwood, B. C. (1988). Multiple cysteine proteinase forms during the life cycle of Dictyostelium discoideum revealed by electrophoretic analysis. Biochemical Journal 254, 261-268.

North, M. J., Franek, K. J. \& Cotter, D. A. (1990). Differential secretion of Dictyostelium discoideum proteinases. Journal of General Microbiology 136, 827-833.

Pears, C. J., Mahbubani, H. \& Williams, J. G. (1985). Characterization of two highly diverged but developmentally co-regulated cysteine proteinase genes in Dictyostelium discoideum. Nucleic Acids Research 13, 8853-8866.

SeshadRI, J., CotTer, D. A. \& Dimond, R. L. (1986). The characterization and secretion pattern of the lysosomal trehalases of Dictyostelium discoideum. Experimental Mycology 10, 131-143.

TISA, L. S. \& COTTER, D. A. (1980). Expression of glycosidase activities during germination of Dictyostelium discoideum spores. Journal of Bacteriology 141, 436-442.

Williams, J. G., North, M. J. \& Mahbubani, H. (1985). A developmentally regulated cysteine proteinase in Dictyostelium discoideum. EMBO Journal 4, 999-1006. 